\title{
Causes of the EU ETS price drop: recession, CDM, renewable policies or a bit of everything? - New evidence
}

\author{
Nicolas Koch ${ }^{1, *}$, Sabine Fuss ${ }^{1,2}$, Godefroy Grosjean ${ }^{3}$, \\ Ottmar Edenhofer ${ }^{1,3,4}$
}

\author{
${ }^{1}$ Mercator Research Institute on Global Commons and Climate Change, Resources and International \\ Trade, Torgauer Straße 12-15, 10829 Berlin, Germany \\ ${ }^{2}$ International Institute for Applied Systems Analysis, Ecosystems Services \& Management, \\ Schlossplatz 1, 2361 Laxenburg, Austria \\ ${ }^{3}$ Potsdam Institute for Climate Impact Research,Telegrafenberg A31, 14473 Potsdam, Germany \\ ${ }^{4}$ Technische Universität Berlin, Strasse des 17, Juni 135, 10623 Berlin, Germany
}

\begin{abstract}
The price of EU allowances (EUAs) in the EU Emissions Trading Scheme (EU ETS) fell from almost $30 € / \mathrm{tCO} 2$ in mid-2008 to less than $5 € / \mathrm{tCO} 2$ in mid-2013. The sharp and persistent price decline has sparked intense debates both in academia and among policy-makers about the decisive allowance price drivers. In this paper we examine whether and to what extent the EUA price drop can be justified by three commonly identified explanatory factors: the economic recession, renewable policies and the use of international credits. Capitalizing on marginal abatement cost theory and a broadly extended data set, we find that only variations in economic activity and the growth of wind and solar electricity production are robustly explaining EUA price dynamics. Contrary to simulation-based analyses, our results point to moderate interaction effects between the overlapping EU ETS and renewable policies. The bottom line, however, is that $90 \%$ of the variations of EUA price changes remains unexplained by the abatement-related fundamentals. Together, our findings do not support the widely-held view that negative demand shocks are the main cause of the weak carbon price signal. In view of the new evidence, we evaluate the EU ETS reform options which are currently discussed.
\end{abstract}

Keywords: EU ETS, carbon price, renewables

JEL: C22, Q42, Q54, Q58

\footnotetext{
* Corresponding author, Email: koch@mcc-berlin.net, tel.: +49 (0) 303385537 231, postal address: Mercator Research Institute on Global Commons and Climate Change, Torgauer Straße 12-15, 10829 Berlin, Germany
} 


\section{Introduction}

The EU Emissions Trading Scheme (EU ETS), considered the flagship climate policy of the European Union, has experienced a sharp decline in permit prices between 2008 and 2013. The price for EU Allowances (EUAs) went from $28 €$ per ton of carbon dioxide $\left(\mathrm{tCO}_{2}\right)$ in mid2008 to $5 € / \mathrm{tCO}_{2}$ at the time of writing this paper. Such depressed permit prices are not likely to provide sufficient incentives for low-carbon technological investments (Nordhaus, 2011) and may increase the risk of carbon lock-in (Clò et al., 2013). This situation has sparked intense debates both in academia and among policy-makers about the reasons of the price drop, its impact on the effectiveness of the trading scheme and options for reform (Clò et al., 2013; European Commission, 2012; Grosjean et al., 2014). To inform the debate, this paper intends to investigate empirically the drivers of the current EUA price movements with a special focus on overlapping climate policies and the role of renewables in particular.

An extensive stream of the literature is devoted to exploring the carbon pricing mechanism. Theory predicts that the permit price should reflect market fundamentals related to the marginal costs of emissions abatement; see e.g. Montgomery (1972) and Rubin (1996). ${ }^{1}$ Fuel switching in the dominant power sector is considered to be the single most important abatement method in the EU ETS (Delarue et al., 2008; Hintermann, 2010) ${ }^{2}$ and, consequently, in an efficient market, prices for input fuels are expected to determine EUA prices. In addition, exogenous factors such as economic activity or weather conditions are identified as relevant price fundamentals, since they determine business-as-usual emissions, i.e. the need for abatement (Hintermann, 2010). Empirical evidence relating to these theoretical expectations is scattered over the different regulatory periods which have been

\footnotetext{
${ }^{1}$ For a recent survey of permit pricing theory, see Bertrand (2013).

${ }^{2}$ This is due to (i) the ability of power generators to abate emissions without either cutting output or building new plants and (ii) the fact that the power and heat sector is dominant within the EU ETS (Kettner et al., 2008).
} 
put in place in the EU ETS. The pilot Phase I covered the period 2005 to 2007. Phase II coincided with the Kyoto Protocol commitment period of 2008 to 2012. Phase III runs from 2013 to 2020. A series of studies empirically analyzes the relevance of the theoretically motivated price drivers in Phase I of the EU ETS (Aatola et al., 2013; Alberola et al., 2008a; Alberola et al., 2008b; Chevallier, 2009; Hintermann, 2010; Mansanet-Bataller et al., 2007). The common finding is that the identified marginal abatement cost drivers had only a limited influence on EUA price formation. Evidence for Phase II is relatively scarce and restricted to early Phase II (until December 2010) when the EUA price was still around $15 € / \mathrm{tCO}_{2}$. The first studies (Bredin and Muckley, 2011; Creti et al., 2012; Koch, 2014) suggest that a new pricing regime with an increased dependency between EUA, fuel and stock prices emerges in the Phase I-to-Phase II period, which may be attributed to advances in the EU ETS market design and maturity. Lutz et al. (2013) recently provide corroborating evidence for the nonlinearity in the relation between EUA, energy and financial prices for the entire Phase II.

However, the economic environment as well as the policy environment of the EU ETS has substantially changed since 2011. In fact, we know very little about the causes of the EU ETS price drop over the last three years which ultimately led to the persistently low EUA price level in 2013. The widely-held view among market participants, academics and policymakers (Grosjean et al., 2014; de Perthuis/Trotignon, 2013) is that three main causes can be put forward to explain the weak EUA price signal: (i) the deep and lasting economic crisis in the European Union (Aldy and Stavins, 2012; European Commission, 2013; Neuhoff et al., 2012), (ii) the overlapping climate policies, e.g. feed-in tariffs for renewables (Fankhauser et al. 2010; Van den Bergh et al., 2013; Weigt et al., 2013), and (iii) the large influx of Certified Emission Reductions (CERs) and Emission Reduction Units (ERUs) in the EU ETS during Phase II (Neuhoff et al., 2012; Newell et al., 2012). However, an accurate assessment of the relative 
importance of the different explanatory factors is an outstanding empirical issue. This examination is all the more important as Koop and Tole (2013) have shown for the Phase Ito-Phase II period that there is substantial turbulence and change in the EU ETS pricing mechanism.

The economic crisis reduces the production of firms covered by the EU ETS, which decreases their demand for EUAs. Simultaneously, grim prospects of economic recovery reinforce the expectations of a lasting low EUA demand, which affects the long-term price trend in the trading scheme. Gloaguen and Alberola (2013) indeed find that the economic downturn plays a significant, but not dominant, role in the decrease of $\mathrm{CO}_{2}$ emissions in EU ETS (see also Declercq et al., 2011). This finding suggests that other structural factors are also relevant for the price formation.

Overlapping policies and more specifically the deployment of renewable energy sources (RES), have been cited as an additional possible explanation of the low EUA price. To reach the EU's 20-20-20 headline targets, ${ }^{3}$ EU Member States have launched generous support mechanisms to stimulate RES deployment, which effectively contributed to a marked expansion of wind and solar capacity in the electricity sector (Edenhofer et al., 2013). The coexistence of EU ETS and RES deployment targets, however, creates a classic case of interaction effects (Goulder, 2013; Levinson, 2010). Theoretical work of Fankhauser et al. (2010) and Fischer and Preonas (2010) suggests that the overlapping policies work at crosspurposes, since RES injections displace $\mathrm{CO}_{2}$ emissions within the EU ETS and thereby reduce the EUA demand and price. ${ }^{4}$ Corroborating the theory, several simulation-based studies

\footnotetext{
${ }^{3}$ It is noteworthy that the legal status of the three goals varies: the GHG emissions reduction and RES share targets are binding while the energy efficiency target is indicative.

${ }^{4}$ In theory, interactions could be mutual: the EU ETS could narrow the cost gap between RES technologies and conventional technologies and therefore stimulate RES deployment. This effect is, however, rather unlikely given the persistent low EUA
} 
predict that RES deployment exercises a strong downward pressure on EUA prices. For instance, simulations in Van den Bergh et al. (2013) suggest that RES deployment reduces the EUA price by $46 €$ in 2008 and more than $100 €$ in 2010. In the simulation of De Jonghe et al. (2009) the allowance price could even drop to zero depending on the stringency of targets (see also Unger and Ahlgren, 2005; Weigt et al., 2013). However, Ellerman et al. (2014) highlight that it remains to be investigated whether the ex post effect of RES on the EUA price is large or small.

Finally, the unexpectedly high use of CERs/ERUs during Phase II of the EU ETS might also contribute to a decreasing EUA demand and price. During the period 2008-2012, companies had already surrendered for compliance more than $60 \%$ of the total permissible $2008-2020$ quota (Point Carbon, 2014). In particular, 2011 and 2012 experienced a high use of Kyoto credits. This might be attributed to the collapse in credit prices (due to the non-ratification of the Kyoto protocol by major emitters) as well as the European Commission's change in the regulations regarding the imports of credits from certain projects. More specifically, in Phase III credits originating from hydrofluorocarbon (HFC) and adipic acid nitrous oxide $\left(\mathrm{N}_{2} \mathrm{O}\right)$ projects are no longer permitted. In addition, new CERs are only allowed if they originate from least-developed countries (Kossoy and Guigon, 2012). As a consequence, companies surrendered for compliance large amounts of cheap credits in the later years of Phase II. For instance, Berghmans and Alberola (2013) estimate that the power sector offsets around $65 \%$ of its shortfall of EUAs using Kyoto credits. In Phase III, however, the policy changes should rather reduce the number of available CERs which may have a positive impact on the price of CERs if demand remains constant.

price level. For instance, Gavard (2012) shows that a carbon price of $46 €$ is necessary to provide a price advantage to wind energy over electricity production from gas. 
Our paper contributes to the literature by quantifying the actual impact of the different explanatory factors on the allowance price in EU ETS based on a broadly extended data set. A quantification of the relative importance of the various price drivers is essential to understanding if and how the EU ETS should be reformed. We expand existing research by conducting a first ex post analysis for the entire Phase II of the EU ETS and the first year of Phase III (January 2008 - October 2013). In particular, we apply extensive data on the deployment of intermittent RES, including monthly electricity production data for wind, solar and hydropower that covers more than $80 \%$ of the (variable) renewable electricity production in the European Union. The ex post data for RES allows us - for the first time - to investigate whether the coexisting of EU ETS and RES targets work at cross-purposes. Previous research has focused on simulation-based modeling approaches and, to the best of our knowledge, no empirical analysis has been carried out.

Our main findings are as follows: we detect a robust and statistically significant - yet at the same time rather modest in terms of magnitude - impact of intermittent renewables underlining the importance of examining overlaps with other policies. Variations in economic activity are indeed the most important abatement-related determinant of EUA price dynamics. The Economic Sentiment Indicator is a particularly useful economic state variable that is robustly explaining EUA price movements. In addition, we find a relatively small influence of CERs on EUA price dynamics. However, this result could be biased due to the limitations of the publicly available CER data which requires us to assume that the number of issued CERs also reflects the number of surrendered CERs in the EU ETS. In total, market fundamentals explain only a minor portion of the price decline in the EU ETS leading us to conclude that further analysis of different types of drivers is necessary. At the same time, reform options solely adjusting the supply of EUA to economic activities or RES 
deployment might not be a panacea. In fact, if a higher and more stable price is seen as necessary to avoid lock-ins and promote long-term cost-effectiveness, it is doubtful that this can be achieved focusing only on these drivers. From this point-of-view and depending on the goals attached to the EU ETS, price instruments such as a price corridor might provide market participants with less uncertainty. Other approaches suggested entail delegation of governance, but the feasibility of implementing this can be questioned (Grosjean et al., 2014).

The paper is structured as follows. Section 2 provides detailed information on the data and methodology used. In section 3, the results are discussed, before the possible implications for the reform proposals are investigated in section 4 . Section 5 concludes.

\section{Methods}

\subsection{Data}

We consider monthly data for the sample period from January 2008 until October, 2013. We have excluded Phase I data because an extensive stream of the literature is already devoted to empirically ascertaining the EUA price drivers in Phase I of the EU ETS, while evidence for the Phase II-to-Phase III period remains scarce.

\section{EUA prices}

We rely on settlement prices of the year-ahead EUA December futures contract traded on the ICE ECX platform to obtain a representative EUA price series. The price data is obtained from ICE Futures Europe, the leading EU ETS trading venue. We rely on futures contracts rather than spot prices because the vast majority of EUA transactions (over $88 \%$ in 2011) are in futures (Kossoy and Guigon, 2012). Further, market microstructure analyses of Mizrach 
and Otsubo (2014) indicate that the ICE ECX is providing between $75 \%$ and $88 \%$ of price discovery for EUA trading. December expiries are the most active contracts. It is noteworthy, however, that both spot and futures prices may contribute interactively to the dynamic process of price discovery in a nonlinear manner, precisely because the relation between EUA spot and futures prices is nonlinear (Arouri et al., 2012). Figure 1 shows the EUA price development over the sample period. In Phase II, the EUA price initially rises to almost $30 €$. With the financial crisis at the turn of the year 2008/09 the price decreases by about $50 \%$. Then, after a moderate price recovery in early 2009 , the price experiences a two-year period of remarkable stability around $15 €$. But mid-2011 the price falls again by around $50 \%$ to a new level of 7-8€ for 2012 before falling to an even lower level of around $5 €$ with the start of Phase III.

[Figure 1 around here]

\section{Explanatory variables}

An extensive stream of the literature confirms the link between EUA prices and fuel prices related to the abatement cost argument discussed above (e.g., Alberola et al., 2008a; Creti et al., 2012; Hintermann, 2010; Mansanet-Bataller et al., 2007). Following this literature, we analyze the fuel switching price effect (i) implicitly by including the gas and coal price and (ii) explicitly by calculating the switching price. The latter indicates the theoretical carbon price which makes electricity producers indifferent between gas-fired and coal-fired generation. The price of gas is the month-ahead futures contract for natural gas negotiated at the National Balancing Point (NBP). We consider this gas price from ICE Futures Europe, since it is the most liquid gas trading point. For the coal price we rely on the month-ahead futures contract of ICE Futures Europe which is priced against Argus/McCloskey's API2 index with delivery to the Amsterdam-Rotterdam-Antwerp (ARA) region. This price series is regarded as 
the primary reference coal price for northwest Europe. We convert the gas price (from Pence/therm) and the coal price (from US\$/t) into $€ / M W h$ using exchange rates provided by the European Central Bank. Finally, the calculated switching price is not only a function of gas and coal prices, but is also determined by the efficiency and emission rate of coal and gas plants in the EU ETS. The latter are taken from Delarue et al. (2010). ${ }^{5}$ Panel (a) of Figure 1 shows the EUA price development, on the one hand, and variations in the fuel (switching) prices on the other hand. The most important feature is that there seems to be evidence of a decoupling of the EUA price and the theoretical carbon switching price since 2011, making it unlikely that fuel switching may explain the continued deterioration of EUA prices.

Economic activity is an important exogenous determinant of business-as-usual emissions and, therefore, EUA demand. To ascertain the expected price effect, we use two forwardlooking indicators of economic activity. First, following the previous literature (e.g., Bredin and Muckley, 2011; Creti et al., 2012; Hintermann, 2010; Lutz et al., 2013), we rely on stock price movements as an indicator of current and expected economic conditions. In addition, the inclusion is motivated by the fact that it allows controlling for market disturbances such as the 2008/09 financial crisis. More specifically, we consider the STOXX EUROPE 600 index, which is a broad benchmark index tracking the performance in 18 European countries (Source: Thomson Datastream). ${ }^{6}$ Second, we propose using the Economic Sentiment Indicator (ESI) published by Eurostat as alternative measure of economic conditions. This confidence indicator combines perceptions and expectations about economic activity in the EU based on business surveys. We present the evolution of the two distinct economic variables in Panel (b) of Figure 1 jointly with the EUA price. In line with expectations, the

\footnotetext{
${ }^{5}$ Coal burned at $36 \%$ efficiency: $951 \mathrm{tCO}_{2} / \mathrm{GWh}$; Gas burned at $50 \%$ efficiency: $413 \mathrm{tCO}_{2} / \mathrm{GWh}$.

${ }^{6}$ We choose a broad-based stock index (rather than a blue-chip index such as the EURO STOXX 50) to ensure that any firm or sector-specific idiosyncrasies in growth prospects are smoothed out.
} 
relatively strong co-movements of the time series indicate that economic activity may be an important explanatory factor of EUA prices. However, linkages are apparently weaker since the second half of 2012.

To account for potential trade-offs between the deployment of electricity from renewable energy sources (RES-E) and the carbon price in an emissions trading regime, we include - for the first time - an extensive data set of renewable energy deployment. The monthly RES-E production data is obtained from the European Network of Transmission System Operators for Electricity (ENTSO-E). The ENTSO-E database provides power system data of all electric Transmission System Operators (TSOs) in the EU in a standardized way. Two RES-E production types are distinguished: firstly, hydro production, which comprises storage hydro, run of river and pumped storage; secondly, other RES-E production which compromises wind and solar. ${ }^{7}$ Data for these two RES-E production variables in GWh is available for Austria, Belgium, France, Germany, Italy, Netherland, Portugal and Spain. The sample accounts for $82 \%$ (44\%) of total electricity production from wind and solar (hydro) in EU ETS countries. The data coverage for hydro is relatively low because our sample excludes the Scandinavian countries (due to data availability). Panel (c) of Figure 1 depicts the opposite movements of the EUA price and wind/solar production. While the deployment of the variable RES steadily increases, the EUA price continuously falls. The observed negative correlation suggests that the coexisting ETS and RES targets may work at cross-purposes.

The use of offsets issued by the project-based mechanisms established under the Kyoto Protocol is another potential price driver of EUAs, since the supply of eligible offsets directly reduces the demand for EUAs. We draw upon the IGES CDM Project Database, which is

\footnotetext{
${ }^{7}$ The inclusion of other RES such as biomass, landfill gas and biogases is not possible because no reliable data is available for the entire period of analysis.
} 
based on official UNFCCC data, to calculate the monthly amount of CERs (in $\mathrm{tCO}_{2}$ ) issued by the CDM Executive Board. Here, we assume that the number of issued CERs also reflects the number of surrendered CERs in the EU ETS. This assumption is technically incorrect, although the EU ETS is the major compliance market accepting CERs. We also note that the inclusion of ERUs was not possible because only yearly data is available. As shown in Panel (d) of Figure 1, CER issuances start off rather slowly, but issuance activity accelerates rapidly after 2011 when EUA prices start falling simultaneously. The observation that times with high CER issuance activity are also times with low EUA prices is in line with the suggestion that the unexpectedly large use of offsets for compliance in 2011 and 2012 may be a driving factor behind the marked EUA price fall.

It is noteworthy that we do not include weather variables. The motivation here is that the price impact of (extreme) weather conditions is indirect through the influence on energy demand (e.g., heating or air conditioning of homes) and carbon-free energy supply (e.g., from hydro, wind or solar power plants). We directly capture the demand/supply effects by using extended data for fluctuation in RES-E production and electricity consumption (in a robustness analysis). Moreover, we do not include highly endogenous variables such as electricity prices or clean spark and dark spread (as in Alberola et al. 2008a; Bredin and Muckley, 2010), since endogeneity may lead to biased estimates of the price drivers in the analysis. In fact, Fell (2010) and Fezzi and Bunn (2009) show that carbon costs are largely passed through to electricity prices in most countries, highlighting the possibility of reverse causality.

\section{Summary statistics}

The stationarity properties of the data are examined through the Augmented-Dickey-Fuller test that tests the null hypothesis that an observable time series contains a unit root (i.e. is 
non-stationary). Results are presented in Panel A of Table 1. While the issued CERs are stationary in log levels, the unit root test suggest taking first differences to obtain stationary time series in all other cases. Consequently, the latter time series are transformed by taking natural logarithms and differencing.

Panel B of Table 1 contains descriptive statistics of the employed stationary variables. In addition, Panel $\mathrm{C}$ shows that the unconditional correlations between the independent variables are generally low and frequently insignificant. Indeed, the absolute values of correlation coefficients indicate that the various proxies reflect distinct and complementary information and that multicollinearity is not present among the explanatory variables. Unsurprisingly, correlations within the same groups (e.g. fuel prices or economic activity) are higher, for instance among gas and switching price changes or stock market returns and changes of the Economic Sentiment Indicator. Finally, we also test for the presence of ARCH effects (i.e. to investigate whether periods of low volatility are followed by periods of high volatility and vice versa) in Panel D. According to the Lagrange Multiplier (LM) test based on Engle (1982), both the dependent variable and the majority of independent variables are homoscedastic during the sample period examined, which is why we do not implement an ARCH parameterization for second moments as in Chevallier (2009), Lutz et al. (2013) or Paolella and Taschini (2008).

[Table 1 around here]

\subsection{Econometric specification}

The most natural way to estimate the relative importance of potential price drivers in the EU ETS is to regress EUA price changes $\left(E U A_{t}\right)$ on the set of exogenous explanatory variables discussed and specified above. This methodology is consistent with existing work of Alberola 
et al. (2008a), Hintermann (2010) and Mansanet-Bataller et al. (2007. It allows us to compare our results to the prior findings and to highlight special features of Phase II and early Phase III. Note however that - from an inter-temporal perspective - EUA prices are not only determined by current abatement options, but also by the future demand paths. Yet, with the notable exception of the economic activity indicators, our explanatory variables cannot capture future expectations as such forward-looking data is not available.

More specifically, we set up the following two model specifications:

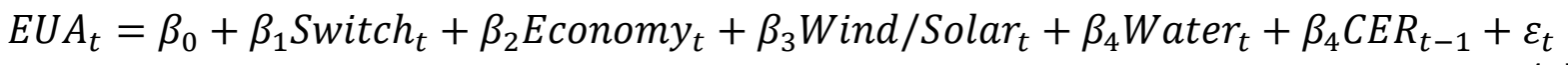

$$
\begin{gathered}
\text { EUA }_{t}=\beta_{0}+\beta_{1} \text { Gas }_{t}+\beta_{2} \text { Coal }_{t}+\beta_{3} \text { Economy }_{t}+\beta_{4} \text { Wind }_{\text {Solar }}+\beta_{5} \text { Water }_{t} \\
+\beta_{6} \text { CER }_{t-1}+\varepsilon_{t}
\end{gathered}
$$

The models only differ with regard to the analysis of fuel switching price effects. While Eq. (2) implicitly accounts for fuel switching by including the price change of gas $\left(\operatorname{Gas}_{t}\right)$ and coal $\left(\right.$ Coal $\left._{t}\right)$, Eq. (1) explicitly includes changes in the theoretical switching price $\left(\right.$ Switch $\left._{t}\right)$.

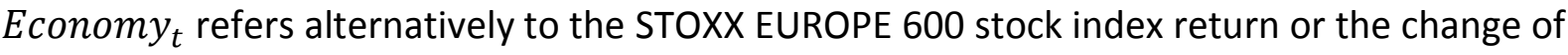
the Economic Sentiment Indicator (to avoid multicollinearity). Wind/Solar ${ }_{t}$ and Water $_{t}$ capture the growth of electricity production from wind/solar and water, respectively. Finally, $C E R_{t-1}$ refers to the number of issued CERs (in natural logarithm) lagged by one period ${ }^{8}$, taking into account the fact that newly issued CERs may not be surrendered immediately in the EU ETS.

We use Ordinary Least Squares (OLS) to estimate the multivariate regression models. Checking the residuals of the OLS estimations $\left(\varepsilon_{t}\right)$, we find strong serial correlation as

\footnotetext{
${ }^{8}$ Estimates using the contemporaneous amount of issued CERs have also been performed. They remain statistically insignificant, indicating that the signals from CER activity seem to be internalized in the EU ETS only with a time lag.
} 
evidenced by the Ljung-Box $Q(k)$ statistics at the $5 \%$ significance level (Table 2). ${ }^{9}$ Most prior analyses include lagged prices (or AR terms) in order to reduce autocorrelation, which results in an improved model fit. However, this sidesteps the question of what actually drives EUA prices. Consequently, we do not follow this procedure. Instead, we base our estimations on the Newey-West covariance matrix. The Newey-West estimator has the important property that standard errors are robust to both ignored autocorrelation in residuals and heteroskedasticity. ${ }^{10}$ Finally, it is noteworthy that a weakness of the singleequation relationship expressed in model (1) and (2) is that any long-term relationships among EUA prices and their fundamentals cannot be estimated as information is lost due to differencing. Therefore, we also carry out cointegration analyses as robustness check.

\section{Results}

Table 2, rows (1) and (2) show the results for Eq. (1) based on switching price, while rows (3) and (4) show the results for Eq. (2) based on the individual fuel prices. The respective rows only differ with regard to the economic activity proxy used. The different regressions reveal a number of interesting conclusions.

[Table 2 around here]

First, for the fuel variables, we find no clear-cut evidence that the abatement costs of fuel switching are reflected in EUA prices. Although the change in the switching price shows the expected positive coefficient estimate, its statistical significance is ambiguous, depending on the economic activity proxy used (ESI vs. stock index). The counter-intuitive finding that the switching price does not necessarily provide statistically significant information may be

\footnotetext{
${ }^{9}$ The Ljung-Box $Q$ statistic tests the null that the first $k$ autocorrelations are all zero against an alternative that at least one is non-zero. The number of lags $k$ is chosen as the largest integer for which $k \leq 2 \sqrt{N}$.

${ }^{10}$ In line with findings for the individual time series, we find no evidence of heteroskedasticity in the residuals based on Engle's (1982) ARCH LM test (Table 2).
} 
explained by the insignificant EUA price sensitivity to coal price changes exposed in rows (3) and (4). In fact, the estimates for coal price changes exhibit the expected negative sign but remain unanimous statistically insignificant. The insignificant coal prices may indeed dampen the explanatory power of the switching variable that combines both gas and coal prices. In contrast, gas price changes seem to convey significant information (at the $5 \%$ and $10 \%$ significance level) about EUA price movements. The positive point estimates for the gas variable are in line with economic theory. Rising gas prices, by reducing the profitability of gas-fired plants, stimulate a switch to more $\mathrm{CO}_{2}$-intensive generation technologies, resulting in higher EUA demand and an upward pressure on EUA prices. Our findings of significant gas price effects but insignificant coal price effects is in agreement with prior studies for Phase I of the EU ETS, e.g. Alberola et al. (2008a), Hintermann (2010) and Mansanet-Bataller et al. (2007). ${ }^{11}$ However, we cannot corroborate the finding of more recent studies using also data from early Phase II (Bredin and Muckley, 2011; Creti et al., 2012; Koch, 2014), which document an increased dependency between fuel prices and allowance prices. The latter studies imply highly significant impacts of gas and coal, which are not reflected in the estimates for the entire Phase II sample at hand.

Second, the estimation results document that variations in expected economic development exhibit a strong influence on EUA price fluctuations. In particular, the coefficient estimates for the ESI are highly significant and indicate that the EUA price is very sensitive to changes in the perceived/expected economic conditions. Ceteris paribus, a $1 \%$ decrease of the ESI is associated with a decrease in the EUA price of approximately $1.2 \%$. Because there are several possible measures of economic activity, we also use stock index returns as an alternative forward-looking indicators of economic activity. Similarly, EUA prices exhibit a

\footnotetext{
${ }^{11}$ Only in Alberola et al. (2008a) the influence of coal proofs to be statistically significant.
} 
statistically significant and positive sensitivity to the stock index returns. The effect is, however, lower in magnitude. The finding that economic activity is robustly explaining EUA price dynamics in our sample period (Phase II / early Phase III) is in stark contrast to the Phase I studies of Chevallier (2009) and Hintermann (2010) that provide weak empirical support for the role of economic activity. However, results in prior research pertaining to early Phase II are corroborated by our analysis (e.g. Creti et al., 2012; Chevallier, 2011; Koch, 2014).

Third, we provide strong new evidence that the development of intermittent renewable energy deployment helps explain EUA price movements. More specifically, the coefficients on the growth of wind and solar electricity production are negative and highly significant across all model specifications. Indeed, an increasing deployment of variable RES appears to be associated with decreasing EUA prices. However, the magnitude of the price elasticity of wind/solar growth $(-0.11 \% /-0.14 \%)$ is relatively small (specifically, in comparison to the price elasticity of economic activity). An important implication of this finding is that the economic impact of intermittent RES on EUA prices seems rather modest. In particular, the empirically moderate effect is in sharp contrast to prior simulation-based studies, which predict strong allowance price reductions. For instance, Van den Bergh et al. (2013) predict RES induced price reductions by $46 €$ in 2008 and more than $100 €$ in 2010 while the allowance price could even drop to zero in De Jonghe et al. (2009). The limited RES effects may be explained by the fact that the actual deployment of RES is relatively consistent with its expected deployment. Although the production of electricity from RES has developed slightly more dynamically than anticipated in the later years of Phase II, the European Commission currently expects to fall short of its $20 \%$ RES target due to the economic crisis without further actions from the member states (European Commission, 2013). Consequently, the extent to which RES 
deployment has reinforced the EUA price decline remains empirically limited. Concerning the impact of hydro power, we also find the expected negative relation between the growth of hydro production and EUA price changes; the effect is, however, not significant at conventional levels. The insignificance may reflect that hydro power, unlike wind and solar, is a mature RES with modest growth rates due to geographical constraints. In addition, our result is consistent with previous studies using reservoir levels or perception as proxy for the supply of hydro power that turn out to have only marginal effects on EUA prices (Hintermann, 2010; Mansanet-Bataller et al., 2007).

Finally, we find a statistically significant negative influence of the issued CERs. However, given the tiny coefficient estimate, the economic significance of CERs seems rather limited. This finding may imply that, contrary to expectations, the use of offsets has not necessarily been a decisive factor impacting the EUA price. Specifically, the minor contribution from the Kyoto credits may be explained on the basis that the maximum use of offsets was anticipated when setting the cap. In fact, only the timing of offset use was different than expected because forward-looking market participants adapted their offset imports to the changing regulation for international credits. However, we believe that the interpretation of this result warrants some caution, since it could be attributed to the limitations of the available data. As outlined above, we have to assume that the number of issued CERs also reflects the number of surrendered CERs in the EU ETS. Obviously, this is technically incorrect and may introduce a bias. Moreover, the inclusion of ERUs was not possible because only yearly data is available. Although we acknowledge these limitations, we included the CER data in the analysis, in particular, to control for effects of the unexpectedly large CER use in 2011 and 2012 discussed above. It is noteworthy that all other estimates remain qualitatively very similar if we exclude the CER data. 
Altogether, our selected abatement-related fundamentals explain about $10 \%$ of the variations of EUA price changes as witnessed by the adjusted $R^{2}$. Consequently, a first key finding of our analysis is that EUA price dynamics cannot be solely explained by marginal abatement cost theory. To highlight our second key finding, Figure 2 shows a decomposition of the $\mathrm{R}^{2}$ into contributions of the different marginal abatement cost drivers (based on Shapley values, see Huettner and Sunder, 2012): approximately $40 \%$ of the explanatory power of the model can be attributed to variations in economic conditions and around $23 \%$ of the $\mathrm{R}^{2}$ relate to the growth of wind and solar deployment. In other words, economic activity and wind/solar deployment are the most important abatement-related drivers of EUA price dynamics. In contrast, the influence of fuel switching is rather small.

[Figure 2 around here]

\section{Robustness checks}

We perform several additional analyses to assess the robustness of our results and methodology. First, we carry out cointegration analyses in order to test whether any longterm relationships between EUA price changes and their fundamentals (namely, fuel prices, economic activity, RES deployment) exists. Based on the Johansen (1991) procedure, we find no evidence of an equilibrium relationship, as we fail to reject the null hypothesis of no cointegration at the $5 \%$ significance level. ${ }^{12}$ Consequently, we cannot confirm the result of Bredin and Muckley (2011) and Creti et al. (2012), who find a cointegration relationship for early Phase II (until December 2010). Given these test results, we conclude that the singleequation relationship expressed in Eqs. (1) and (2) seem appropriate to describe EUA price

\footnotetext{
${ }^{12}$ Due to space limitations results are not presented here. They are available upon request.
} 
dynamics. For the sake of brevity, we present all subsequent robustness analyses on the basis of the more parsimonious model specification of Eq. (1). ${ }^{13}$

Second, we check whether our results are influenced by the choice of the indicator of economic activity. Instead of using forward-looking indicators as above, we select a backward-looking indicator, namely the Industrial Production Index - Manufacturing published by Eurostat, which tracks the past output and activity of the manufacturing industry in the EU (as in Alberola et al., 2008b). The results of this analysis are reported in row (1) of Table 3 and show that the backward-looking economic measure provides no statistically significant explanatory power, while all other estimates remain qualitatively very similar. The finding indicates that the EUA price is rather determined by expectations of future economic conditions (captured by the ESI or the stock index) than by current economic activity, which may be explained by a forward-looking behavior of market agents. In addition, we use oil price changes as an alternative (forward-looking) proxy for economic activity. ${ }^{14}$ In fact, oil prices are included in several prior analyses (e.g., Alberola et al., 2008a; Creti et al., 2012), although the motivation for the inclusion is not clear because the switch from oil to gas is not likely to be a marginal abatement activity (Hintermann, 2010). Instead, Koch (2014) finds that the positive price impact of oil can be attributed to the correlation between oil prices and overall economic activity rather than to fuel switching or oil-gas correlation. More, specifically, we rely on the month-ahead futures contract for Brent crude oil, extracted from ICE Futures Europe. The results reported in row (2) of Table 3 show that the oil price changes are also statistically insignificant, while all other coefficients remain unchanged.

\footnotetext{
${ }^{13}$ All robustness analyses have also been performed based on Eq. (2) with the results remaining qualitatively the same.

${ }^{14}$ We find that the inclusion of both the oil prices and the ESI (or the stock index) leads to multicollinearity. Thus, we decide to use the variables separately.
} 
[Table 3 around here]

Third, we check whether our results are influenced by the inclusion of electricity consumption data. The inclusion is motivated by the fact that many prior studies use weather indices (mostly based on extreme temperatures) as explanatory variable (Alberola et al., 2008a; Hintermann, 2010; Mansanet-Bataller et al., 2007) because weather conditions indirectly influence energy demand (e.g., heating or air conditioning of homes). Instead of constructing such an approximate measure for energy consumption, we use monthly electricity consumption data (in GWh) published by ENTSO-E for Austria, Belgium, France, Germany, Italy, Netherland, Portugal and Spain. ${ }^{15}$ Row (3) of Table 3 shows that the seasonality-adjusted electricity consumption values do not have a significant influence on the EUA prices. In a similar vein, we also examine whether our results (in particular for the deployment of RES) are influenced by seasonal patterns by including a set of seasonal dummy variables. The unreported results of this analysis show that all seasonal dummies are statistically insignificant, while inferences about the abatement-related fundamentals are very consistent.

Finally, given that $90 \%$ of the EUA price variation remains unexplained by our marginal abatement cost model, we seek to investigate whether policy events explain EUA price dynamics. To this end, we add a set of dummy variables for selected policy announcements, namely the ban on the use of certain CERs (January 2011), the proposal for an energy efficiency directive (June 2011), the intention to link the EU ETS with Australia (August 2012), the backloading proposal (November 2012), the report on structural options to strengthen the EU ETS (December 2012), the green paper on the 2030 framework (March 2013) and the

\footnotetext{
${ }^{15}$ Since the data series exhibits significant seasonal patterns, we regress the log consumption values on a constant and three season dummies and use the stationary residuals of this regression as explanatory variable.
} 
first and second vote by the European Parliament on the backloading proposal (April 2013 and July 2013). ${ }^{16}$ The inclusion of event dummies reveals two interesting findings (row 4 of Table 3). First, the extended model explains $44 \%$ of the variation in price changes (in terms of the adjusted $\mathrm{R}^{2}$ ). Most policy dummies are highly significant and show the expected sign. However, there are three notable exceptions, which bring us to the second important finding. More specifically, the report on structural measures and the green paper on the 2030 framework both aim at a more stringent EUA supply in the future. Similarly, the backloading proposal implies a stricter short-term EUA supply by postponing the auctioning of 900 million allowances from $2013-15$ to $2019-20$ (the overall supply is not changed). To be successful, the announced reform policies should alter market expectation and should, indeed, have a positive price impact. But effectively the announcements of backloading and structural measures seem to coincide with statistically significant price falls, while the effect of the 2030 framework remains insignificant. This result indicates that the announced reform policies do not change the current perception of market agents that the EUA price will remain low for long periods. The underlying reason may be a lack of credibility on the EU's reform proposals as discussed in Brunner et al., (2012) and Lecuyer and Quirion (2013). The low credibility can arise from (i) the uncertainty and inconsistency of medium-term targets and (ii) the inherent credibility problems of any long-term commitment. However, it is important to note that we use monthly event dummies, which may be imprecise for studying the impact of an announcement on a certain day. In the light of this major limitation, our results should be carefully interpreted as a first indication of a credibility problem that needs further investigation.

\footnotetext{
${ }^{16}$ The strategy to use dummy variables to control for institutional features is also carried out in Alberola (2008b) and Mansanet-Bataller et al. (2011).
} 


\section{Discussion}

What are the implications of our results in terms of the choice of a reform option? In fact, the necessity of intervention depends to a great extent on the goals attached to the EU ETS (Grosjean et al., 2014). In a short-term cost-effectiveness paradigm, for instance, low prices do not require intervention. A sufficiently high price might be seen as desirable, however, in order to avoid lock-ins, sustain investment in low carbon technologies and ensure long-term cost-effectiveness (Clò et al., 2013). Other reasons for a higher price might also include reflecting the social cost of carbon (Nordhaus, 2011). As discussed in Grosjean et al. (2014), the reform options can be broadly categorized along two dimensions (i) the degree of price certainty embodied in the reform option and (ii) the degree of delegation - i.e. the extent to which the governance of the carbon market is delegated to a rule-based mechanism or an independent institution. In that context, if the need for reform is identified, the type of options favored depends on what is seen as the main driver of the low price.

Based on our results, it seems questionable whether reform proposals solely focusing on making the EU ETS 'demand shocks proof' will be sufficient if the low price is seen as undesirable. In fact, a rule adjusting the cap to expected economic development or renewable deployment as proposed by IETA (2013) might not deliver a desirable price level (i.e. depending on the goals attached to the EU ETS) due to the limited impact demand shocks appear to have on the EUA price formation. Similarly, a rule adjusting the release of allowances to the surplus in the market, such as the Market Stability Reserve suggested by the European Commission (2014), might suffer from the same drawback. From such a perspective, a price instrument such as a price corridor or a price floor might offer a better option to send a clear signal to market participants (Fell and Morgenstern 2009; Wood and Jotzo, 2011). A price floor can be implemented as an auction reserve price in the EU ETS, i.e. 
an auction is only released when the auction price is beyond a pre-defined minimum price. In general, a price collar would generate three potential market outcomes: (i) when EUA demand is low, the price is set by the floor, and emissions are below the annual cap; (ii) when demand is moderate, the EUA price is somewhere between the floor and ceiling, and the emissions are determined by the cap; and (iii) when demand is high, the price is set by the ceiling, and emissions are above the cap. Thus, the hybrid price-quantity mechanism would directly reduce the price uncertainty in the EU ETS.

The policy-event dummies give us some evidence, although limited, that regulatory uncertainty might play a role in price formation. This finding, if confirmed, would imply different reform options than the ones merely aimed at adjusting to short-term shocks (e.g. due to economic downturn or large renewable deployment). Such reform options should seek to stabilize the expectations of market participants. From this perspective, two types of approaches are discussed in the literature: (i) reducing policy uncertainty and (ii) decreasing the long-term commitment problem (Brunner et al., 2012). The former induces for instance the establishment of mid- to long-term legally binding $\mathrm{CO}_{2}$ emissions reduction targets. The current debate is focusing on the 2030 targets but to ensure long-term cost effectiveness, it might be necessary to provide to market participants a long-term decarbonization pathway. Nonetheless, as discussed in Grosjean et al. (2014) such a strategy might not be sufficient to bring the necessary level of stability to the expectations of market participants.

Tackling the long-term commitment problem in order to stabilize expectations is a delicate task. In monetary policy, the experience has favored delegation in setting the money supply as a tool to overcome the problem (Barro and Gordon, 1983; Kydland and Prescott, 1977; Rogoff, 1985). In the context of the reform of the EU ETS, one could foresee the delegation of the governance of the carbon market to an independent authority whose goal would be 
to ensure that the short-term EUA price is in line with long-term target (e.g. Clò et al., 2013; de Perthuis and Trotignon, 2013). However, this will not be without difficulties. The exact mandate of this institution as well as the instrument used to achieve its goal will not be easily defined (Grosjean et al., 2014). Nonetheless, what an independent authority may achieve is a smoother decision-process for making reforms as well as locating the decision outside of the political sphere (Newell et al., 2012). This might create more stable expectations on the way decisions are taken over time, even if the goals are modified to adapt to new information and circumstances.

Based solely on the empirical findings discussed in this paper, it is difficult to assess exactly what type of reform is needed. However, it gives additional insight on the (limited) role of abatement-related fundamentals on price development, in particular with new results on the impact of renewables. In addition, it gives new evidence that regulatory uncertainty might negatively impact the EUA price, potentially undermining the ability of the EU ETS to deliver long-term cost-effectiveness. These are nonetheless very preliminary findings and further research is needed to better understand the relation between regulatory uncertainty and price formation as well as its influence on long-term cost-effectiveness.

\section{Conclusion and Policy Implications}

The price of EU allowances in the EU ETS fell from almost $30 €$ in mid-2008 to less than $5 €$ in mid-2013. In this paper we look for reasons behind the sharp and persistent decline of EUA prices in Phase II and early Phase III of the EU ETS. In particular, we examine whether and to what extent the EUA price drop can be justified by abatement-related fundamentals derived from permit market theory. Based on a broadly extended data set, we quantify the actual 
impact of three commonly identified explanatory factors of the low EUA price: the economic recession, renewable policies and the use of international credits.

We find that EUA price dynamics cannot be solely explained by marginal abatement cost theory. The set of abatement-related fundamentals explains only about $10 \%$ of the variations of EUA price changes. Specifically, $40 \%$ of the explanatory power of the model can be attributed to variations in expected economic conditions. Our results suggest that the Economic Sentiment Indicator is a particularly useful economic state variable that is robustly explaining EUA price movements. Consistent with theories suggesting that the coexistence of EU ETS and RES deployment targets work at cross-purposes, we also find that the growth of wind and solar electricity production is a second important determinant of EUA price drops. However, the estimated ex post sensitivity of EUA price changes to wind/solar growth is much smaller than predicted ex ante by simulation-based studies. The important implication of this finding is that policy interaction effects between ETS and RES targets are empirically moderate and potentially exaggerated in simulation-based analyses. Finally, our results do not support the view that the large use of offsets is related to the EUA price fall. Although we find a statistically significant negative influence of the issued CERs, the economic relevance of CERs on EUA price dynamics seems rather limited. However, we stress again the potential bias in this result which may emerge from the necessary assumption that the number of issued CERs also reflects the number of surrendered CERs in the EU ETS.

Given that $90 \%$ of the EUA price variation remains unexplained by abatement-related fundamentals, it is necessary in further research to identify the true allowance price drivers. Although a conclusive answer to this question exceeds the scope of this paper, our robustness analysis suggests that policy events and a lack of credibility may be alternative 
explanations for the weak price signal. Indeed, a preliminary analysis of policy announcement effects suggests that several announced reform policies apparently do not change the current perception of market agents that the EUA price will remain low for long periods. However, the use of monthly event dummies may be too imprecise for studying the impact of policy events on market expectation and EUA prices. We believe that a key issue for future research is to verify whether structural weaknesses - and a lack of credibility in particular - are at the root of the inefficient carbon pricing mechanism. This is crucial in order to structure the debate on the reform proposals for the EU ETS, in particular in the framework of options delegating (at varying degrees) the governance of the EU ETS.

\section{Acknowledgements}

The authors would like to thank the participants of the Euro-CASE workshop in Brussels in February 2014 for their valuable feedback and, in particular, Brigitte Knopf, Christian Flachsland and various colleagues at MCC and PIK for their constructive comments on the study. 


\section{References}

Aatola, P., Ollikainen, M. and A. Toppinen, 2013. Price determination in the EU ETS market: Theory and econometric analysis with market fundamentals. Energ Econ 36, 380-395.

Aldy, J. and N. Stavins, 2012. The promise and problems of pricing carbon: theory and experience. J Environ Dev 21(2), 152-180.

Alberola, E., Chevalier, J. and B. Chèze, 2008a. Price Drivers and Structural Breaks in European Carbon Prices 2005-07. Energ Policy 36(2), 787-797.

Alberola, E., Chevalier, J., and B. Chèze, 2008b. The EU Emissions Trading Scheme: the Effects of Industrial Production and CO2 Emissions on European Carbon Prices. Int Econ 116, 93-126.

Arouri, M., Jawadi, F. and D.K. Nguyen, 2012. Nonlinearities in carbon spot-futures price relationships during Phase II of the EU ETS. Economic Modelling 29, 884-892.

Barro, R.J., and D. Gordon, 1983. A positive theory of monetary policy in a natural rate model. J Polit Econ 91 , 589-610.

Berghmans, N., and E. Alberola, 2013. The power sector in phase 2 of the EU ETS - fewer carbon emissions, but just as much coal. CDC Climat Climate Report 42.

Bertrand, V., 2013. Modeling of Emission Allowance Markets: A Literature Review, Climate Economics Chair Working Paper 2013-04.

Bredin, D. and C. Muckley, 2011. An Emerging Equilibrium in the EU Emissions Trading Scheme. Energ Econ $33(2), 353-362$.

Brunner, S., Flachsland, C. and R. Marschinski (2012). Credible commitment in carbon policy. Clim Policy 12(2), 255-271.

Chevallier, J., 2009. Carbon futures and macroeconomic risk factors: A view from the EU ETS. Energ Econ 31(4), $614-625$

Chevallier, J., 2011. A model of carbon price interactions with macroeconomic and energy dynamics. Energ Econ 33, 1295-1312.

Clò, S., Battles, S. and P. Zoppoli, 2013. Policy options to improve the effectiveness of the EU emissions trading system: a multi- criteria analysis. Energ Policy 57, 477-490.

Creti, A., Jouvet, P.A. and V. Mignon, 2012. Carbon Price Drivers: Phase I versus Phase II Equilibrium? Energ Econ 34(1), 327-334.

Declercq, B., Delarue, E. and W. D'haeseleer, 2011. Impact of the economic recession on the European power sector's CO2 emissions. Energ Policy 39, 1677-1686.

Delarue, E., Voorspools, K. and W. D'haeseleer, 2008. Fuel switching in the electricity sector under the EU ETS: review and prospective. J Energ Eng-Asce 134, 40-46.

Delarue, E., Ellerman, A.D. and W. D’haeseleer, 2010. Robust MACCs? The topography of abatement by fuel switching in the European power sector. Energy 35, 1465-1475.

DeJonghe, C., Delarue, E., Belmans, R. and W. D'haeseleer, 2008. Interactions between measures for the support of electricity from renewable energy sources and CO2 mitigation. Energ Policy 37, 4743-4752. 
Edenhofer, O., Hirth, L., Knopf, B., Pahle, M., Schlömer, S., Schmid, E. and F. Ueckerdt, 2013. On the economics of renewable energy sources. Energ Econ 40, 12-23.

Ellerman, A.D., Marcantonini, C. and A. Zaklan, 2014. The EU ETS: Eight Years and Counting. EUI Working Paper RSCAS 2014/04.

Engle, R. F., 1982. Autoregressive conditional heteroskedasticity with estimates of the variance of United Kingdom inflation. Econometrica 50, 987-1007.

European Commission, 2012. The State of the European Carbon Market in 2012, Report from the Commission to the European Council and Parliament, Brussels.

European Commission, 2013. Green Paper. A 2030 framework for climate and energy policies.

European Commission, 2014. Proposal for a Decision of the European Parliament and of the Council concerning the establishment and operation of a market stability reserve for the Union greenhouse gas emission trading scheme and amending Directive 2003/87/EC.

Fankhauser, S., Hepburn, C. and J. Park, 2010. Combining multiple climate policy instruments: how not to do it. Clim Change Econ 1(3), 209-225.

Fell, H. (2010). EU-ETS and Nordic Electricity. Energy Journal 31, 1-26.

Fell, H. and R. Morgenstern, 2009. Alternative approaches to cost containment in a cap-and-trade system, Resources for the Future Discussion Paper RFF DP 09-14.

Fezzi, C. and D.W. Bunn, 2009. Structural interactions of European carbon trading and energy prices. J Energ Mark 2, 53-69.

Fischer, C. and L. Preonas, 2010. Combining Policies for Renewable Energy. Is the Whole Less than the Sum of Its Parts? Int Rev Environ Resour Econ 4(1), 51-92.

Gavard, C., 2012. Carbon price as renewable energy support? Empirical analysis on wind power in Denmark. EUI Working Paper RSCAS 2012/19.

Gloaguen, A. and E. Alberola, 2013. Assessing the factors behind CO2 emissions changes over the phases 1 and 2 of the EU ETS: an econometric analysis. CDC Climat Research Working Paper 2013-15.

Goulder, L.H., 2013. Markets for Pollution Allowances: What Are the (New) Lessons? J Econ Perspect 27(1), 87102.

Grosjean, G., Acworth, W., Flachsland, C. and R. Marschinski, 2014. After monetary policy, climate policy: is delegation the key to EU ETS reform? MCC Working Paper, February 2014.

Hintermann, B., 2010. Allowance price drivers in the first phase of the EU ETS. J Environ Econ Manage 59, 4356.

Huettner, F. and M. Sunder, 2012. Axiomatic arguments for decomposing goodness of fit according to Shapley and Owen values. Electronc J Stat 6, 1239-1250.

International Emissions Trading Association (IETA), 2013. Initial IETA reflections on the concept of an "Automatic Adjustment of Auction Volumes" in the EU ETS. Retrieved from: http://www.ieta.org/assets/EUWG/ieta_reflection_flexible_supply_paper_02.10.2013_final.pdf

Johansen, S., 1991. Estimation and Hypothesis Testing of Cointegration Vectors in Gaussian Vector Autoregressive Models. Econometrica 59, 1551-1580. 
Kettner, C., Köppl, A., Schleicher, S. P. and G. Thenius, 2008. Stringency and distribution in the EU emissions trading scheme: first evidence. Clim Policy 8, 41-61.

Koch, N., 2014. Dynamic linkages among carbon, energy and financial markets: a smooth transition approach. Appl Econ 46(7), 715-729.

Koop, G. and L. Tole, 2013. Forecasting the European carbon market. J. R. Statist. Soc. A 176(3), 723-741.

Kossoy, A. and P. Guigon, 2012. States and trends of the carbon market 2012, World Bank.

Kydland, F., and E.C. Prescott, 1977. Rules rather than discretion: the inconsistency of optimal paths. J Polit Econ 85, 473-492.

Lecuyer, O. and P. Quirion, 2013. Can uncertainty justify overlapping policy instruments to mitigate emissions? Ecol Econ 93(C), 177-191.

Levinson, A., 2010. Belts and Suspenders: Interactions Among Climate Policy Regulations. NBER Working Paper 16109.

Lutz, B.J., Pigorsch, U. and W. Rotfuß, 2013. Nonlinearity in cap-and-trade systems: The EUA price and its fundamentals. Energ Econ 40, 222-232.

Mansanet-Bataller, M., Pardo, A. and E. Valor, 2007. CO2 prices, energy and weather. Energ J 28, 73-92.

Mansanet-Bataller, M., Chevallier, J., Hervé-Mignucci, M. and E. Alberola, 2011. EUA and sCER phase II price drivers: Unveiling the reasons for the existence of the EUA-sCER spread. Energ Policy 39, 1056-1069.

Mizrach, B. and Y. Otsubo, 2014. The market microstructure of the European climate exchange. J Bank Financ 39, 107-116.

Montgomery, D.W., 1972. Markets in licenses and efficient pollution control programs. J Econ Theory 5, 395418.

Neuhoff, K., Schopp, A., Boyd, R., Stelmakh, K. and A. Vasa, 2012. Banking of Surplus Emissions Allowances: Does the Volume matter? DIW Discussion Papers 1193: 1-21.

Newell, R. G., Pizer W. A. and D. Raimi, 2012. Carbon Markets: Past, Present, and Future. NBER Working Paper 18504.

Nordhaus, W., 2011. Designing a friendly space for technological change to slow global warming, Energ Econ 33, 665-673.

Paolella, M. And L. Taschini, 2008. An econometric analysis of emission-allowance prices. J Banking Financ 32, 2022-32.

de Perthuis, C. and R. Trotignon, 2013. Governance of CO2 markets: Lessons from the EU ETS, Climate Economics Chair Working Paper 2013-07.

Point Carbon, 2013. Use of credits for compliance within EU ETS nearly doubles 2012 levels. Retrieved from: http://www.pointcarbon.com/aboutus/pressroom/pressreleases/1.2383916

Rogoff, K., 1985. The optimal degree of commitment to a monetary target. Q J Econ 100, 1169-1190.

Rubin, J.D., 1996. A model of intertemporal emission trading, banking, and borrowing. J Environ Econ Manage 31, 269-86. 
Unger, T. and E.O. Ahlgren, 2005. Impacts of a common green certificate market on electricity and CO2emission markets in the Nordic countries. Energ Policy 33, 2152-2163.

Van den Bergh, K., Delarue, E. and W. D'haeseleer, 2013. Impact ofrenewables deployment on the CO2 price and the CO2 emissions in the European electricity sector. Energ Policy 63, 1021-1031.

Weigt, H., Ellerman, A.D. and E. Delarue, 2013. CO2 abatement from renewables in the German electricity sector: Does a CO2 price help? Energ Econ 40, 149-158.

Wood, P.J. and F. Jotzo, 2011. Price floor for emissions trading. Energ Policy 39, 1746-1753. 


\section{Figures}
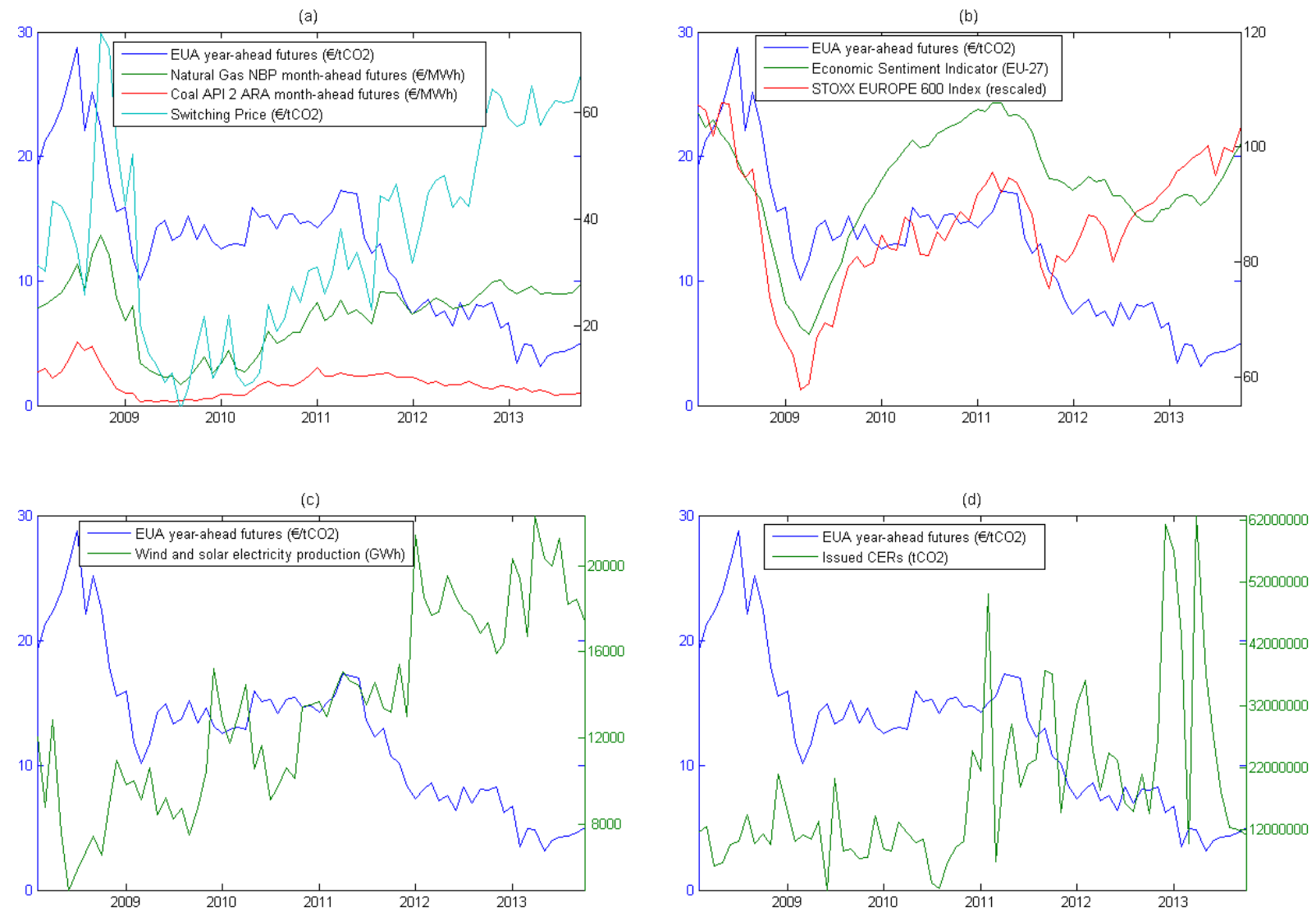

Fig. 1. Evolution of EU Allowance (EUA) prices (on the left $y$-axis) jointly with (a) fuel (switching) prices, (b) indicators of economic activity, (c) the deployment of electricity from renewable energy sources and (d) the amount of issued Certified Emissions Reductions (CERs) (on the right y-axis, respectively). 


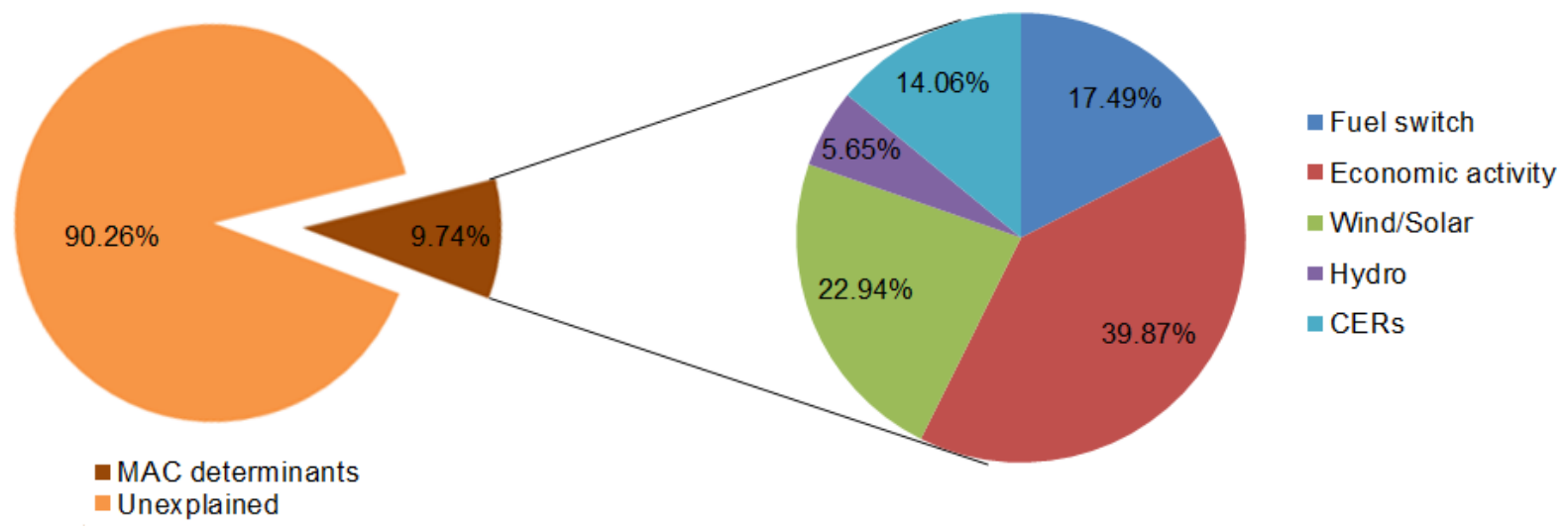

Fig. 2. Decomposition of the adjusted $R^{2}$ based on the estimation of Eq. (1) in row (1) of Table 2 into contributions of the different marginal abatement cost (MAC) drivers based on Shapley values. 


\section{Tables}

\section{Table 1: Summary statistics}

Panel A reports test statistics of the Augmented-Dickey-Fuller (ADF) test for monthly data for EU Allowance futures (EUA), NBP natural gas futures (Gas), API2 coal futures (Coal), STOXX EUROPE 600 index (Stock), Economic Sentiment Indicator (ESI), electricity production from wind/solar and hydro and the amount of issued Certified Emissions Reductions (CERs). Panel B presents descriptive statistics of the stationary time series used in the analysis. Panel $\mathrm{C}$ reports the corresponding cross-correlations of the variables. Panel $\mathrm{D}$ presents statistics for ARCH LM tests based on Engle (1982). The sample period is from January 2008 to October 2013. *,**, and $* * *$ denote significance at $10 \%, 5 \%$ and $1 \%$ levels, respectively.

\begin{tabular}{|c|c|c|c|c|c|c|c|c|c|}
\hline & EUA & Switch & Gas & Coal & Stock & ESI & $\begin{array}{c}\text { Wind/ } \\
\text { Solar }\end{array}$ & Hydro & $\begin{array}{c}\text { Issued } \\
\text { CERs }\end{array}$ \\
\hline \multicolumn{10}{|c|}{ Panel A: Augmented-Dickey-Fuller Test } \\
\hline Level & -1.16 & -1.62 & -2.36 & -1.78 & -1.69 & -2.64 & 0.04 & 0.52 & $-4.53 * * *$ \\
\hline Log-difference & $-10.86 * * *$ & $-8.67 * * *$ & $-3.79 * * *$ & $-6.83 * * *$ & $-5.25 * * *$ & $-2.57 * *$ & $-5.22 * * *$ & $-1.80^{*}$ & - \\
\hline \multicolumn{10}{|c|}{ Panel B: Descriptive Statistics } \\
\hline Mean (ann.) & -0.24 & 0.13 & 0.03 & -0.08 & -0.01 & -0.01 & 0.06 & -0.01 & 198.24 \\
\hline Std. Dev. (ann.) & 0.57 & 1.13 & 0.47 & 0.33 & 0.17 & 0.09 & 0.62 & 0.52 & 2.39 \\
\hline Skewness & -1.02 & -0.42 & -1.42 & -0.48 & -0.55 & -0.60 & -0.07 & -0.00 & -0.16 \\
\hline Kurtosis & 5.71 & 4.53 & 7.96 & 3.93 & 3.68 & 3.79 & 4.02 & 2.28 & 3.30 \\
\hline \multicolumn{10}{|c|}{ Panel C: Unconditional Correlations } \\
\hline EUA & 1.00 & 0.16 & $0.26 * *$ & 0.20 & $0.21 *$ & $0.21 *$ & -0.18 & -0.10 & $-0.26 * *$ \\
\hline Switch & & 1.00 & $0.87 * * *$ & 0.14 & -0.08 & 0.13 & -0.17 & -0.11 & -0.08 \\
\hline Gas & & & 1.00 & $0.54 * * *$ & 0.07 & $0.24 * *$ & $-0.21 *$ & -0.05 & -0.12 \\
\hline Coal & & & & 1.00 & $0.27^{* *}$ & $0.25 * *$ & $-0.27 * *$ & 0.15 & -0.15 \\
\hline Stock & & & & & 1.00 & $0.61 * * *$ & -0.16 & -0.03 & -0.08 \\
\hline ESI & & & & & & 1.00 & -0.03 & -0.07 & $-0.22 *$ \\
\hline Wind/Solar & & & & & & & 1.00 & -0.06 & 0.08 \\
\hline Hydro & & & & & & & & 1.00 & 0.19 \\
\hline Issued CERs & & & & & & & & & 1.00 \\
\hline \multicolumn{10}{|c|}{ Panel D: ARCH Test } \\
\hline $\begin{array}{l}\text { ARCH LM } \\
\text { statistics }\end{array}$ & 0.77 & 2.46 & 0.28 & 4.21 & 0.63 & 3.91 & 3.44 & 0.00 & 14.64 \\
\hline$p$-value & 0.38 & 0.12 & 0.60 & 0.04 & 0.43 & 0.05 & 0.06 & 0.99 & 0.00 \\
\hline
\end{tabular}




\section{Table 2: Estimation results}

The table shows the coefficient estimates for the regression model, estimated with OLS and Newey-West covariance matrix. Rows (1) and (2) show the results for Eq. (1) based on the switching price, while rows (3) and (4) show the results for Eq. (2) based on the individual fuel prices. Diagnostic tests are reported below. $Q(12)$ is the Ljung-Box Q statistic for serial correlation up to a lag length of 12. The ARCH LM (1) test is based on Engle (1982) and allows for one lag. For the sake of brevity, we do not report the estimated intercept (available upon request). The $\mathrm{p}$-value is given in parentheses.

\begin{tabular}{|c|c|c|c|c|}
\hline & (1) & $(2)$ & (3) & (4) \\
\hline \multicolumn{5}{|l|}{ Fuel Price Variables } \\
\hline \multirow[t]{2}{*}{ Switch } & 0.0679 & 0.0937 & & \\
\hline & $(0.1135)$ & $(0.0284)$ & & \\
\hline \multirow[t]{2}{*}{ Gas } & & & 0.2606 & 0.3254 \\
\hline & & & (0.0579) & $(0.0224)$ \\
\hline \multirow[t]{2}{*}{ Coal } & & & -0.0911 & -0.1368 \\
\hline & & & $(0.7294)$ & (0.6079) \\
\hline \multicolumn{5}{|l|}{ Economic Activity Variables } \\
\hline \multirow[t]{2}{*}{ Economic Sentiment Index } & 1.282 & & 1.1622 & \\
\hline & $(0.0031)$ & & $(0.0173)$ & \\
\hline \multirow[t]{2}{*}{ Stock Index } & & 0.7058 & & 0.6679 \\
\hline & & $(0.0108)$ & & $(0.0255)$ \\
\hline \multicolumn{5}{|c|}{ Renewable Energy Source Variables } \\
\hline \multirow[t]{2}{*}{ Wind/Solar } & -0.1462 & -0.1102 & -0.1408 & -0.1106 \\
\hline & $(0.0007)$ & $(0.0297)$ & $(0.0035)$ & (0.0399) \\
\hline \multirow[t]{2}{*}{ Hydro } & -0.0275 & -0.0282 & -0.0258 & -0.0246 \\
\hline & $(0.7060)$ & $(0.7048)$ & (0.6698) & $(0.7042)$ \\
\hline \multicolumn{5}{|l|}{ International Offset Variable } \\
\hline \multirow[t]{2}{*}{ Issued CERs (-1) } & -0.0067 & -0.0075 & -0.0066 & -0.0073 \\
\hline & $(0.0223)$ & (0.0169) & $(0.0284)$ & $(0.0220)$ \\
\hline$R^{2}$ & 0.1782 & 0.1778 & 0.1952 & 0.1983 \\
\hline adjusted $\mathrm{R}^{2}$ & 0.0974 & 0.097 & 0.1013 & 0.1047 \\
\hline AIC & -3.6264 & -3.626 & -3.6473 & -3.6512 \\
\hline $\mathrm{BIC}$ & -3.398 & -3.3975 & -3.4188 & -3.4227 \\
\hline \multirow[t]{2}{*}{$Q(12)$} & 21.2568 & 23.7297 & 23.7005 & 26.5957 \\
\hline & $(0.0467)$ & $(0.0221)$ & $(0.0223)$ & $(0.0088)$ \\
\hline \multirow[t]{2}{*}{ ARCH LM (1) } & 0.7825 & 0.9059 & 0.7849 & 0.9132 \\
\hline & (0.3764) & $(0.3412)$ & $(0.3756)$ & (0.3393) \\
\hline
\end{tabular}




\section{Table 3: Robustness estimation results}

The table shows the OLS coefficient estimates for Eq. (1) using alternative indicators of economic activity (row 1 and 2), controlling for electricity consumption patterns (row 3) and including selected policy announcements (row 4). For the sake of brevity, we do not report the estimated intercept (available upon request). The p-value is given in parentheses.

\begin{tabular}{|c|c|c|c|c|}
\hline & (1) & (2) & (3) & (4) \\
\hline \multirow[t]{2}{*}{ Switch } & 0.0767 & 0.0961 & 0.0731 & 0.027 \\
\hline & (0.0970) & $(0.0356)$ & $(0.0806)$ & (0.4072) \\
\hline \multirow[t]{2}{*}{ Economic Sentiment Index } & & & 1.302 & 1.5853 \\
\hline & & & $(0.0026)$ & $(0.0000)$ \\
\hline \multirow[t]{2}{*}{ Wind/Solar } & -0.1515 & -0.1061 & -0.1306 & -0.1849 \\
\hline & (0.0033) & $(0.0786)$ & (0.0038) & (0.0007) \\
\hline \multirow[t]{2}{*}{ Hydro } & -0.0426 & -0.0486 & -0.0064 & 0.0157 \\
\hline & $(0.6011)$ & $(0.4668)$ & (0.9433) & (0.8342) \\
\hline \multirow[t]{2}{*}{ Issued CERs (-1) } & -0.0055 & -0.0045 & -0.0067 & -0.0014 \\
\hline & $(0.0985)$ & $(0.0316)$ & $(0.0225)$ & $(0.8052)$ \\
\hline \multirow[t]{2}{*}{ Industrial Production } & 0.6922 & & & \\
\hline & (0.6087) & & & \\
\hline \multirow[t]{2}{*}{ Oil } & & 0.4053 & & \\
\hline & & $(0.1313)$ & & \\
\hline \multirow[t]{2}{*}{ Electricity Consumption } & & & -0.2068 & \\
\hline & & & (0.5518) & \\
\hline \multirow[t]{2}{*}{$\mathrm{D}$ (CER ban) } & & & & 0.0489 \\
\hline & & & & (0.0088) \\
\hline \multirow[t]{2}{*}{ D(Energy Efficiency) } & & & & -0.2264 \\
\hline & & & & $(0.0000)$ \\
\hline \multirow[t]{2}{*}{$\mathrm{D}$ (Linking Australia) } & & & & 0.1737 \\
\hline & & & & $(0.0000)$ \\
\hline \multirow[t]{2}{*}{$\mathrm{D}$ (Backloading proposal) } & & & & -0.3189 \\
\hline & & & & $(0.0000)$ \\
\hline \multirow[t]{2}{*}{$\mathrm{D}$ (Structural measures) } & & & & -0.7094 \\
\hline & & & & $(0.0000)$ \\
\hline \multirow[t]{2}{*}{ D(2030 framework) } & & & & 0.0298 \\
\hline & & & & $(0.2291)$ \\
\hline \multirow[t]{2}{*}{$\mathrm{D}$ (Backloading vote 1 ) } & & & & -0.4225 \\
\hline & & & & $(0.0000)$ \\
\hline \multirow[t]{2}{*}{$\mathrm{D}$ (Backloading vote 2 ) } & & & & -0.0401 \\
\hline & & & & (0.1313) \\
\hline $\mathrm{R}^{2}$ & 0.1367 & 0.1895 & 0.1818 & 0.5487 \\
\hline adjusted $\mathrm{R}^{2}$ & 0.0518 & 0.095 & 0.0864 & 0.44 \\
\hline
\end{tabular}

